\title{
Pensamento Negro em Educação: Acesso de Estudantes Negros ao Ensino Superior após uma Década de Tensões e Desafios
}

\author{
VIEIRA, Paulo Alberto dos Santos ${ }^{1}$ \\ SOUSA, Karina Almeida de ${ }^{2}$
}

\section{RESUMO}

Em setembro de 2015, o Conselho de Ensino, Pesquisa e Extensão da Universidade do Estado de Mato Grosso prorrogou por mais dez anos o Programa de Integração e Inclusão Étnico-racial (Piier/Unemat), que se traduz nas cotas para negros desta universidade. Nesta reunião chamou a atenção algumas situações: a. posição da maioria do pleno, amplamente favorável à prorrogação; b. mudança de posição em relação às cotas, na medida em que alguns atores que eram contrários em 2005 discursaram em prol da continuidade do programa; e c. absoluta ausência de qualquer tipo de dado e/ou informação oficial referente ao Piier. Neste artigo, argumenta-se que a aprovação da prorrogação não significou que as políticas de ação afirmativa, com recorte étnico-racial, sejam apoiadas. Paradoxalmente, a prorrogação pode ter por base a consolidação de práticas acadêmicas que tendem a dificultar, e no limite impedir, a presença negra no interior da universidade bem comouma reaorientação curricular.

Cotas para negros. Fraudes. Unemat. Mato Grosso. Educação. Diáspora.

\section{Black thinking in education: Black students' access to higher education after one decade of tensions and challenges}

\begin{abstract}
In September 2015, the "Conselho de Ensino, Pesquisa e Extensão da Universidade do Estado de Mato Grosso" extended for another ten years the "Programa de Integração e Inclusão Étnico-racial (Piier/Unemat)", which translates into the affirmative action policies for black people in this university. In this meeting, some situations drew attention: a. the position of the majority of the plenary, broadly favorable to the program extension; b. changing position in relation to affirmative action policies for black people, as some social actors who
\end{abstract}

\footnotetext{
${ }^{1}$ Doutor em Sociologia. Professor do Magistério Superior da Universidade do Estado do Mato Grosso (UNEMAT). E-mail: vieirapas@yahoo.com.br. Lattes:

http://lattes.cnpq.br/1723860927289572. Orcid: https://orcid.org/0000-0003-1894-9954.

2 Mestre em Sociologia. Professora do Magistério Superior da Universidade Federal do Tocantins (UFT). E-mail: sousakarina@mail.uft.edu.br. Lattes:

http://lattes.cnpq.br/7080534523571723. Orcid: https://orcid.org/0000-0002-2552-2046.
}

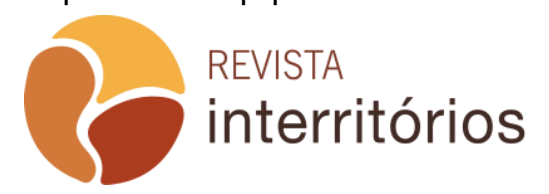

Interritórios | Revista de Educação Universidade Federal de Pernambuco, Caruaru, BRASIL | V.6 N.12 [2020] 
were opposed in 2005 spoke in favor of the continuity of the program; and c. absolute absence of any type of data and/or official information regarding Piier. In this article, it is argued that the approval of the extension did not mean that affirmative action policies, with ethnic-racial aspects, are supported by the community. Paradoxically, the extension may be based on the consolidation of academic practices that tend to hinder, and in the end prevent, the black people presence within the university as well as a curricular reorientation.

Affirmative action policies for black people. Fraud. Unemat. Mato Grosso. Education. Diaspora.

\section{Pensamiento negro en la educación: Acceso de estudiantes negros a la educación superior tras una década de tensiones y desafíos}

\section{RESUMEN}

En septiembre de 2015, el Consejo de Enseñanza, Investigación y Extensión de la Universidad del Estado de Mato Grosso extendió el Programa de Integración e Inclusión Étnico-Racial (Piier / Unemat) por otros diez años, lo que se traduce en las cuotas de negros de esta universidad. En este encuentro, algunas situaciones llamaron la atención: a. posición de la mayoría del plenario, ampliamente favorable a la prórroga; b. cambio de posición en relación a las cuotas, ya que algunos actores que se opusieron en 2005 se pronunciaron a favor de la continuidad del programa; y c. ausencia absoluta de cualquier tipo de dato y / o información oficial sobre "Piier". En este artículo se argumenta que la aprobación de la prórroga no significó que se apoyen políticas de acción afirmativa, con aspectos étnico-raciales. Paradójicamente, la extensión puede basarse en la consolidación de prácticas académicas que tienden a dificultar, y finalmente a prevenir, la presencia negra dentro de la universidad así como una reorientación curricular.

Cuotas para negros. Fraude. Unemat. Mato Grosso. Educación. Diáspora.

\section{Pensiero nero ne la educazione: accesso degli studenti neri all'istruzione superiore dopo un decennio di tensioni e sfide}

\section{SOMMARIO}

A settembre 2015, il Consiglio per l'insegnamento, la ricerca e l'estensione dell'Università statale del Mato Grosso ha prorogato per altri dieci anni il programma di integrazione e inclusione etnico-razziale (Piier / Unemat), che si traduce in quote nere di questa università. In questo incontro, alcune situazioni hanno attirato l'attenzione: a. posizione della maggioranza della plenaria, ampiamente favorevole all'estensione; b. cambiamento di posizione rispetto alle quote, poiché alcuni attori che si erano opposti nel 2005 si erano espressi a favore della continuità del programma; e C. assoluta assenza di qualsiasi tipo di dato e / o informazione ufficiale su "Piier". Questo articolo sostiene che 
l'approvazione dell'estensione non significa che siano supportate politiche di azione affermativa, con aspetti etnico-razziali. Paradossalmente, l'estensione può essere basata sul consolidamento di pratiche accademiche che tendono a ostacolare, e infine a prevenire, la presenza nera all'interno dell'università così come un riorientamento curricolare.

Quote nere. Frode. Unemat. Mato Grosso. Formazione scolastica. Diaspora.

\section{INTRODUÇÃO}

Parece existir certo consenso em torno da utilização de políticas de ação afirmativa em sociedades em que o escravismo, como estratégia primeira do colonialismo delimitou e continua delimitando os arranjos societários, políticos e econômicos, para além das dinâmicas de sociabilidade. Nessas sociedade, como o Brasil, os Estados Unidos da América e a Índia, os grupos sociais aos quais as ações afirmativas tem se destinado vivenciaram os processos de racialização e consequente desumanização.

Deste ponto de vista, as políticas de ação afirmativa têm, dentre outros, o objetivo de assegurar o cumprimento constitucional da igualdade no âmbito dos direitos ao acesso a espaços formativos e decisórios. No caso brasileiro, quando nos referimos às políticas de ação afirmativas no âmbito educacional entendemos que essas políticas deixam para trás a noção de igualdade material, substituindo-a pela noção de igualdade imaterial.

No Brasil, a implementação de políticas de ação afirmativa remonta às primeiras décadas do século XX. Em termos normativos é muito provável que a primeira ação desta natureza, em termos gerais, esteja inscrita na Consolidação das Leis do Trabalho.

Decreto 5.452 de 01 de maio de 1943 que estatuiu as normas que passaram a regular as relações individuais e coletivas de trabalho previa, em seu Capítulo II - Da Nacionalização do Trabalho - Seção I - Da Proporcionalidade de Empregados Brasileiros uma série de ações que visavam equiparar, no mercado de trabalho, a relação entre empregadores e empregados brasileiros e estrangeiros.

Se avançarmos analiticamente, ainda no século XX é possível encontrar um grande número de leis e outras iniciativas junto aos Órgãos Públicos, empresas, organizações não governamentais, sindicatos, partidos políticos cujos objetivos são o de equilibrar a participação de grupos sociais subalternizados seja pela carência econômica, pertença étnico-racial, orientação sexual, crença religiosa, compleição física e/ou nacionalidades em funções de poder, reconhecimento, afirmação e visibilidade. 
De maneira inadequada parte da literatura (VIEIRA, 2007) vinha afirmando ser experiências realizadas no ensino superior como "bons" exemplos de políticas de ação afirmativa no ensino superior.

A experiência realizada entre 1968 e 1986, cujo respaldo era a Lei 5.465/68, conhecida como Lei do Boi, apesar de ter os contornos de uma política de ação afirmativa, resultou em contemplar setores da sociedade brasileira que já dispunham de poder, prestígio e visibilidade. O primeiro artigo da mencionada legislação abria brechas que foram ampla e majoritariamente por quem já detinha terra e outros recursos materiais e simbólicos. $O$ artigo $1^{\circ}$ da Lei $5.465 / 68$ trazia a seguinte redação

Art $1^{\circ}$ Os estabelecimentos de ensino médio agrícola e as escolas superiores de Agricultura e Veterinária, mantidos pela União, reservarão, anualmente, de preferência, de $50 \%$ (cinqüenta por cento) de suas vagas a candidatos agricultores ou filhos dêstes, proprietários ou não de terras, que residam com suas famílias na zona rural e 30\% (trinta por cento) a agricultores ou filhos dêstes, proprietários ou não de terras, que residam em cidades ou vilas que não possuam estabelecimentos de ensino médio.

Ao longo do século XX é possível identificar como o campo normativo foi se modificando no sentido de assegurar materialidade jurídica ao princípio constitucional da igualdade prorrogado na Constituição Federal de 1988. Contudo, deve-se ter atenção e cuidado com eventuais conclusões que, apressadamente, possam autorizar o protagonismo dos atores e das cortes jurídicas em todo este processo.

A importância destes atores realmente é grande, entretanto os resultados em prol da materialização do princípio constitucional da igualdade parecem residir na relação e dinâmica que os movimentos sociais têm com o Estado Nacional e outros importantes atores sociais.

Esta afirmação parece encontrar respaldo nos desdobramentos observados desde meados da década de 1970, quando a sociedade passou a questionar com maior contundência a ditadura militar que se instalara no ano de $1964^{3}$. Os "novos movimentos sociais" também passam a ser mais evidentes a

\footnotetext{
${ }^{3}$ A ditadura militar criou o bipartidarismo. De um lado a Aliança Renovadora Nacional (ARENA) que buscava atribuir sustentação política à ditadura. De outro o Movimento Democrático Brasileiro (MDB) que em 1974 lançou se presidente como anti-candidato às eleições presidenciais daquele ano, disputada no Colégio Eleitoral. Com a candidatura de Ulysses Guimarães (1916-1992) a ditadura militar começava seu processo de derrocada promovida pelas forças sociais democráticas e pelos, assim denominados, "novos movimentos sociais". Para maiores informações sobre o político Ulysses Guimarães e sua participação nas eleições presidenciais de 1974, consultar:
} 
partir deste período e o fim da década de 1970, com todas as manifestações, culturais, sociais e políticas expressavam o descontentamento crescente da população brasileira, sobretudo dos setores mais organizados e os desgastes experimentados pela ditadura militar e suas políticas: econômica, social, industrial, de desenvolvimento econômico etc.

Os novos movimentos sociais surgiram a partir da emergência tanto na esfera das lutas e organizações sociais quanto das reflexões de cunho acadêmico nesse caso a partir dos estudos culturais.

Interessa observar que a dinâmica social que proporcionou, por exemplo, a retomada da pauta identitária por intermédio da criação do Movimento Negro Unificado (MNUDR/1978), recebeu pouco atenção dos intérpretes das mudanças que vinham ocorrendo na sociedade brasileira sobretudo a partir da segunda metade da década de 1970.

Uma das mais instigantes interpretações desse período permaneceu circunscrita à dimensão da categoria trabalho e não capta a multiplicidade de atores coletivos que emergem neste período. De acordo com Sader (1988, p. 25)

\begin{abstract}
o historiador Kazumi Munakata afirmava que o 'acontecimento político mais importante do primeiro semestre deste ano não foi a indicação do General Figueiredo para a Presidência da República [...] nem o surgimento da candidatura dissidente do senador Magalhães Pinto, nem tampouco a articulação da Frente Nacional de Redemocratização. Foi, na realidade, a irrupção do movimento grevista, que, iniciado em meio à região do $A B C$ (SP), rapidamente se alastrou pelos grandes centros industriais e urbanos do Estado, envolvendo centenas de milhares de trabalhadores. No momento em que escrevo, 9 anos depois [...] a afirmação feira por Kazumi [...] corre até 0 risco de parecer banal. Mas é preciso que nos situemos naquele momento [...] É muito provável que na história política do país o período entre 1978 e 1985 [..] fique marcado como momento decisivo na transição para uma nova forma de sistema político" [grifos nossos].
\end{abstract}

No âmbito da produção acadêmica as reflexões partiram do descentramento da categoria trabalho, em razão da emergência e visibilidade das categorias descritivas das marcas sociais da diferença que foram e continuam sendo, muitas vezes, socialmente construídas no espaço da marginalidade e direcionadas às posições sociais subalternas incorporando grupos foram majoritariamente compostos grupos marginalizados e uma nova classe trabalhadora. Serão esses os principais atores que iram compor os Novos

https://cpdoc.fgv.br/producao/dossies/Jango/biografias/ulisses_guimaraes 
Movimentos Sociais (NMS).

O cenário de emergência das diversas posições de sujeito e de uma espécie de polifonia de vozes somou-se à emergência de novos atores sociais, o grau de modificação na sociedade e cultura ocidental, da relação entre a vida privada e a ação coletiva.

Acreditando na transformação cultural, na importância dos novos atores sociais e da ação destes últimos nas esferas da vida social: a vida privada e a vida cultural estavam na arena política, associada a inflexão intelectual e militante promovida pelo movimento de mulheres que mostrou que a vida privada é mais do que nunca coisa pública. Neste sentido, vale ressaltar o lembrete dado por Hall,

(...) não existia um "novo movimento social" naquela época. Para nós, isso não representava uma nova fase (ou forma) da política. Achávamos que se trata ainda do velho jogo político, que conduzíamos de uma nova maneira. Somente quando olhamos para trás é que percebemos que a Nova Esquerda foi uma primeira antecipação da era dos "novos movimentos sociais (Hall, 2006, p.400)

Este ambiente de intensa pugna política em torno da construção de bases democráticas para a sociedade brasileira não esteve isento dos debates acerca das políticas de ação afirmativa que - como dizíamos - foram adotadas para diferentes grupos sociais.

A partir da promulgação da Constituição Federal de 1988 essas políticas, também consagradas na Carta Cidadã, são tomadas como exemplos exitosos para a consecução dos objetivos de redução das assimetrias entre grupos sociais.

Assim, questões como nacionalidade, compleição física, religiosidade, gênero, geração dentre outros marcadores sociais da diferença e da desigualdade são contempladas com reais possibilidades de superação das assimetrias geradas por um sistema histórico que tende a promover 0 crescimento econômico de maneira seletiva, fazendo com que seus beneficiários usufruam privilégios com roupagem de direitos da cidadania, que por décadas a fio, desde o nascimento da República, parece ter encontrado dificuldades para seu pleno desenvolvimento no interior da sociedade brasileira (BRASIL, TST, 2014: p. 27 e CARVALHO, 2011).

\section{Políticas de ação afirmativa: conceito, histórico e experiências}

No debate sobre as políticas de ação afirmativa, independentemente da 
modalidade que pudesse ser adotada, o que se viu no Brasil, sobretudo entre 2002 e 2012, foi um debate que polarizou posições. Esta década "iniciou" com a implementação de políticas de ação afirmativa nas universidades brasileiras, a partir das experiências das universidades fluminenses (UERJ e UENF) e foi "concluída" com a manifestação de constitucionalidade de tais medidas pelo Supremo Tribunal Federal. Entre 2002 e 2012 muito se produziu no debate público que se instalou na sociedade brasileira, avançando sobre a pertinência ou não, sobre a justiça contida neste tipo de ação.

Ao referir-se a este período alguns autores assinalam que o debate também ocorria em torno da categoria raça como conceito possível de estar na base da formação do pensamento social brasileiro quando o foco é a desigualdade. Deste ponto de vistas destacamos uma destas observações

se as posições se acirravam em torno do tema, e este parecia não receber tratamento adequado, uma vez que as políticas de ação afirmativa são amplamente conhecidas e largamente utilizadas desde as primeiras décadas do século XX, por quais motivos o consenso crítico não se preocupou em historicizar os usos de políticas de ação afirmativa em décadas anteriores? Os críticos das cotas para negros, por exemplo, desenvolviam esforços no sentido de refutar tais medidas, mas ao mesmo tempo não remetiam este tema para a experiência sobre as políticas de ação afirmativa acumulada anteriormente no interior da sociedade brasileira [...] Para estes intérpretes, que reconhecem diversos níveis de desigualdades, a raça não teria centralidade e poder explicativo acerca das desigualdades sociais [...] Entretanto, quanto ao tema cotas para negros, certo consenso crítico, como já se frisou, pareceu se formar no debate público travado ao longo de uma década (2002-2012), isto é, entre as primeiras medidas adotadas por universidades fluminenses e a Lei 12.711/122 que tornou obrigatório a adoção de cotas - com recorte socioeconômico e étnico-racial - em instituições federais de ensino superior (VIEIRA, 2015: p. 25 e 26).

Depreende-se da passagem anterior que mesmo amplamente difundidas pela sociedade brasileira, as políticas de ação afirmativa passaram a ser profundamente interrogadas, em um primeiro momento, a partir do século XXI quanto a sua pertinência, validade e legitimidade e posteriormente quanto a legitimidade daqueles e daquelas que passaram a ocupar os espaços/vagas garantidos pelas ações afirmativas pensadas na esfera do acesso ao ensino superior ${ }^{4}$.

\footnotetext{
${ }^{4} \mathrm{O}$ debate sobre os procedimentos de identificação no que tange à declaração dos candidatos à vagas em certames que preveem cotas, ganhou capítulo adicional e polêmico em 2018. A Portaria Normativa n. 4/2018 do Ministério do Planejamento, Desenvolvimento e Gestão/Secretaria de Gestão de Pessoas introduz o princípio da heteroidentificação
} 
E ainda que parte-se de uma leitura em que a desigualdade é "tropo" para a racialização e não o oposto. Este tensionamento ocorreu apenas quando mecanismos já tradicionais e de largo uso pela sociedade e presentes na legislação brasileira, como é indicativo das políticas de ação afirmativa, estenderam-se a negros e indígenas. Neste debate há muitoas questões que emergem da dinâmica das relações raciais no Brasil. Para Bernardino-Costa, Santos Sivério (2009: p. 220) é necessário que se destaque que

os argumentos e prognósticos favoráveis e contrários às cotas raciais [...] sinalizam que esse debate representa uma disputa simbólica pela definição simbólica da nação. O que está em jogo é a) uma reafirmação de um universalismo que não cumpre a sua promessa, a saber, o tratamento igualitário de todos os cidadãos brasileiros independentemente das suas características raciais; e b) a possibilidade de refundação de um novo pacto social que supere o racismo, que permita a redução das desigualdades sociorraciais e o acesso igualitário de negros (pretos e pardos), indígenas, amarelos e brancos a todas as instâncias da sociedade.

Portanto, há de inserir outras questões no debate que se polarizou, particulamente, entre 2002 e 2012. Nota-se que a dicotomia favoráveis versus contrários parece ter sido "inventada", visto que essas políticas enquanto instrumentos afirmativos que buscavam a realização material do princípio constitucional pareciam não constituir aspectos polêmicos da vida nacional até a tomada do debate público sobre o acesso de negros e indígenas.

Não caberá detalhar esta perspectiva neste momento, visto o escopo que se pretende neste texto, mas pode-se inferir que o debate travado ainda merecerá atenção de pesquisadores sobre este tema - o da política de ação afirmativa.

Mas, afinal o que são as políticas de ação afirmativa ? Optamos por uma definição que parece encontrar amplo consenso entre pesquisadores deste tema. De acordo com Gomes (2001: pp. 06 e 07) as políticas de ação afirmativa

consistem em políticas públicas (e também privadas) voltadas à concretização do princípio constitucional da igualdade material e à neutralização dos efeitos da discriminação racial, de gênero, de idade, de origem nacional e de compleição física. Impostas

complementar à autodeclaração, o que em si já se encontrava em alguns programas de ação afirmativa em universidades. Esta Portaria Normativa também determina que a heteroidentificação se dará, exclusivamente, em bases fenotípicas. E aqui nos parece estar o elemento mais polêmico e contraditório no manejo e na gestão das políticas de ação afirmativa. O mencionado documento pode ser acessado em: <https://www.in.gov.br/materia//asset_publisher/Kujrw0TZC2Mb/content/id/9714349/do1-2018-04-10-portaria-normativa-n-4de-6-de-abril-de-2018-9714345> 
ou sugeridas pelo Estado, por seus entes vinculados e até mesmo por entidades puramente privadas, elas visam a combater não somente as manifestações flagrantes de discriminação, mas também a discriminação de fundo cultural, estrutural, enraizada na sociedade. De cunho pedagógico e não raramente impregnada de um caráter de exemplaridade, têm como meta, o engendramento de transformações culturais e sociais relevantes, inculcando nos atores sociais a utilidade e a necessidade da observância dos princípios do pluralismo e da diversidade nas mais diversas esferas do convívio humano. Constituem, por assim, dizer, a mais eloquente manifestação da moderna ideia de Estado promovente, atuante, eis que de sua concepção, implantação e delimitação jurídica participam todos os órgãos estatais essenciais, aí incluindo-se o Poder Judiciário, que ora se apresenta no seu tradicional papel de guardião da integridade do sistema jurídico como um todo, ora como instituição formuladora de políticas tendentes a corrigir as distorções provocadas pela discriminação. Construção intelectual destinada a viabilizar a harmonia e a paz social, as ações afirmativas, por óbvio, não prescindem da colaboração e da adesão das forças sociais ativas, o que equivale dizer que, para seu sucesso, é indispensável a ampla conscientização da própria sociedade acerca da absoluta necessidade de se eliminar ou de se reduzir as desigualdades sociais que operam em detrimento de minorias.

Como se percebe as políticas de ação afirmativa são um amplo conjunto de iniciativas, públicas ou privadas, obrigatórias ou não, cujo enraizamento se dá em sociedades marcadas pelo processo colonial, este por sua vez como propulsor daquilo que Pratt (1992) nomeia como zona de contato.

Segundo Mary Pratt (1992, p.07), a zona de contato enquanto "o espaço em que os povos geográfica e historicamente separados entram em contato produzindo relações contínuas que envolvem condições de coerção, desigualdade radical e conflito intratável"5[tradução livre], estabelece no encontro colonial e na viagem transatlântica, momentos fundacionais de uma perspectiva diaspórica que integra os trânsitos e produz uma rede autorreferenciada de contatos.

Logo, a tensão em torno dessas políticas se configura, porquanto da sua extensão para uma gama bastante diversa de marcadores sociais da diferença que, no entanto, também são apreendidos de formas diversas pela opinião pública, pelo debate acadêmico e político quanto a superação de desigualdades, compreendidas em uma chave pedagógica e sociológica que extrapola as dimensões econômico-classistas- nacionalistas.

\footnotetext{
5 the space of colonial encounters, the space in which peoples geographically and historically separated come into contact with each other and establish ongoing relations, usually involving conditions of coercion, radical inequality, and intractable conflict.
} 
Diferentemente do que se possa imaginar o debate sobre as políticas de ação afirmativa e como nos informam Pereira e Zientarski (2011: p 494) nasceram na Índia e não nos Estados Unidos, muito embora boa parte da influência do debate brasileiro tenha se relacionado à experiência estadunidense. Por outro lado, aprendemos com alguns autores (MOEHLECKE, 2002) que a utilização de políticas desta natureza jamais foram restritas em todo o mundo.

Independentemente do sistema político, da configuração das políticas econômicas, da localização geográfica, das dimensões sócio-históricas dos estados nacionais, da presença de populações supostamente mais ou menos homogêneas sob o prisma étnico e cultural, dos patamares do Índice de Desenvolvimento Humano (IDH), da dimensão do Produto Interno Bruto(PIB) pode-se identificar experiências múltiplas da mobilização das políticas de ação afirmativa. Nas palavras da autora

\begin{abstract}
Experiências semelhantes ocorreram em vários países da Europa Ocidental, na Îndia, Malásia, Austrália, Canadá, Nigéria, África do Sul, Argentina, Cuba, dentre outros. Na Europa, as primeiras orientações nessa direção foram elaboradas em 1976, utilizando- se frequentemente a expressão ação ou discriminação positiva. Em 1982, a discriminação positiva foi inserida no primeiro Programa de Ação para a Igualdade de Oportunidades da Comunidade Econômica Européia. Nesses diferentes contextos, a ação afirmativa assumiu formas como: ações voluntárias, de caráter obrigatório, ou uma estratégia mista; programas governamentais ou privados; leis $\mathrm{e}$ orientações a partir de decisões jurídicas ou agências de fomento e regulação. Seu público-alvo variou de acordo com as situações existentes e abrangeu grupos como minorias étnicas, raciais, e mulheres. As principais áreas contempladas são o mercado de trabalho, com a contratação, qualificação e promoção de funcionários; o sistema educacional, especialmente o ensino superior; e a representação política (MOEHLECKE, 2002: p. 199).
\end{abstract}

Deste modo, pode-se concluir que as políticas de ação afirmativa possuem um longo percurso histórico e larga disseminação em diferentes contextos societários que tensionam as dimensões étnicas e raciais as quais se convencionou pensar os Estados nacionais contemporâneos.

Seja a modalidade adotada ou as áreas onde se verifica a maior incidência desta política, o fundamental na utilização destes mecanismos é o engendramento de oportunidades que contribuam com a superação das assimetrias verificadas entre distintos grupos sociais, e como exposto, políticas com objetivos similares tem se disseminado pelo globo, majoritariamente, 
vinculadas a reparações históricas, econômicas e educacionais daqueles grupos que foram subalternizados como princípio colonial.

No caso do Brasil, a diáspora africana, como fruto das experiências da dor, do desenraizamento e do trânsito produziram zonas de contato que, no Novo Mundo orientaram dinâmicas muitos específicas de sociabilidade intragrupo e no que tange as relações extra -grupo quanto ao acesso a direitos e reconhecimento.

Do século XIX aos dias atuais, a consciência de que a discriminação racial é uma situação a ser combatida tem perpassado os mais distintos espaços e formas de elaboração dos grupos negros e de orientação as suas demandas, particularmente, quanto as suas demandas a sociedade mais ampla, como é o caso das políticas de ações afirmativas para negros.

Segundo as autoras Gusmão e Simson (1989, p. 219-220), a experiência histórica da diáspora negra, nos leva a considerar que ela não tenha ocorrido de maneira igual em todos os lugares. O que nos leva a considerar que a mobilidade geográfica a que foram submetidos os povos africanos tem sido tratada como se o povo africano fosse apenas um, ou ainda se houvesse apenas uma forma de ser negro, desconsiderando as histórias distintas e a condição particular do negro na diversidade.

Entendemos diáspora aqui enquanto deslocamentos étnicos, culturais e territoriais transnacionais que colocam em questionamento a noção dos Estados-Nação enquanto correspondentes a um espaço homogêneo e, portanto , dos negros e de suas demandas como homogêneas.

A partir da compreensão de que existem nações dentro de um mesmo Estado, e mesmo comunidades que não reconhecem o Estado, a diáspora amplia as reflexões para além das fronteiras nacionais traçadas pelo EstadoNação. Em larga medida essa nova condição de reflexão não apenas questiona a "homogeneidade" linguística, política e cultural, mas, por meio de elementos culturais, religiosos e mesmo étnicos torna possível que se estabelecem continuidades para além das fronteiras nacionais. Segundo Gusmão e Simson (1989, p. 219) a diáspora

envolveria processos de circulação de um povo, vivenciando mobilidade geográfica, induzida ou não, possibilidade contraditórias para o estabelecimento de "raízes". (...) Assim, ações criativas dos povos como sujeitos de sua história, isto é, ações mobilizadoras em seu próprio proveito, formas e contextos de luta em mutação; transformações psicoculturais e ideológicas; redes sociais e dinâmicas institucionais constituemse em exemplos de experiência histórica compartilhada. 
Portanto, relacionar de modo unívoco as políticas de ação afirmativa com a modalidade cotas não reflete exatamente o alcance destas medidas. As cotas são tão somente uma das muitas possibilidades que o desenho institucional das políticas de ação afirmativa pode receber em uma dada situação. Estes aspectos nos parecem relevantes para situarmos o debate das políticas de ação afirmativa que, no Brasil, passaram a ser incidentes no ensino superior a partir de $2002 \mathrm{e}$ foram institucionalmente adotadas em todos na educação a partir do ano de 2012 com a implementação da Lei $12.645 / 12^{6}$.

\section{Cotas para negros na UNEMAT: uma década de tensões e desafios}

Em dezembro de 2004, em sessão ordinária, o Conselho de Ensino, Pesquisa e Extensão da Universidade do Estado de Mato Grosso (UNEMAT), após aproximadamente 05 (cinco) hora de intensos debates aprovava por 10 (anos) anos e sem um único voto contrário, a Minuta de Resolução que dava base ao Programa de Integração de Inclusão Étnico-racial da Unemat (Piier/Unemat) ${ }^{7}$. Em setembro de 2015 este mesmo Conselho, também em sessão ordinária, aprovava a prorrogação do Programa por igual período ${ }^{8}$.

Diferentemente da sessão ordinária de fins de 2004, a de 2015 ocorreu de forma tranquila e a prorrogação sequer provocou debates. Ainda que não

\footnotetext{
${ }^{6}$ Em 2015 o debate sobre cotas para negros e indígenas já alcançava os cursos de pósgraduação, conforme destacam Vanali e Silva (2019). No momento em que escrevemos alguns Programas de Pós-graduação já implementaram políticas de ação afirmativa sensíveis à pertença étnico-racial, como são exemplo o Programa de Pós-graduação em Educação da Universidade Federal de Juiz de Fora, no Programa de Antropologia Social da Universidde Federal do Rio de Janeiro e dos Programas de Pós-graduação em Sociologia da Universidade de Brasília e da Universidade Federal de São Carlos, dentre outros.

7 Trata-se da RESOLUÇÃO №. 200/2004 do Conselho do CONEPE da Unemat "Aprova o Programa de Integração e Inclusão ÉtnicoRacial da Universidade do Estado de Mato Grosso. $O$ Presidente do Conselho de Ensino, Pesquisa e Extensão - CONEPE, da Universidade do Estado de Mato Grosso - UNEMAT, no uso de suas atribuições legais, e considerando o Processo s/n, a Portaria no 328/2004 e decisão do Conselho tomada em sessão ordinária do CONEPE realizada nos dias 13 e 14 de dezembro de 2004. RESOLVE: Art. 1ํ Aprovar o Programa de Integração e Inclusão ÉtnicoRacial da Universidade do Estado de Mato GrossoUNEMAT. CAPÍTULO I, DO ACESSO Art. $2^{\circ}$ Disponibilizar, a partir do Concurso Vestibular $2005 / 2$ e por um período de 10 (dez) anos, 25\%(vinte e cinco) por cento das vagas de todos processos seletivos da UNEMAT, para estudantes negros, em cada um dos cursos regulares de graduação, modalidades diferenciadas e turmas especiais oferecidos por esta Instituição de Ensino Superior, excetuando-se o $3^{\circ}$ grau Indígena. $\S 1^{\circ}$ Serão considerados negros, para efeitos desta Resolução, os candidatos que se enquadrarem como pretos ou pardos, conforme classificação adotada pelo Instituto Brasileiro de Geografia e Estatística-IBGE.

8 Com a consolidação das cotas para negros em cursos de graduação, a partir de 2012, iniciouse ampla mobilização para a implementação de cotas nos Programas de Pós-graduação. 0 debate atual sobre a incidência de cotas em cursos de mestrado e doutorado parece retomar, de alguma maneira, argumentos amplamente conhecidos e debatidos. Experiências como as da UnB, da UFSCar e outras universidades demonstram o alcance que estas políticas têm alcançado no Brasil, apesar de algumas vozes contrárias.
}

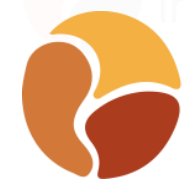

Interritórios | Revista de Educação Universidade Federal de Pernambuco, Caruaru, BRASIL | V.6 N.12 [2020] 
fosse apresentado um único dado ou uma única avaliação do Piier/Unemat e aqueles atores que foram contrários uma década antes, manifestaram-se favoravelmente è prorrogação.

Esse contexto, refletido em sua historicidade foi o elemento propulsor para as reflexões apresentadas neste texto., ou seja, o tensionamento das políticas de ações afirmativas, fundamentado pelas alterações quantitativas e, portanto, perceptíveis na maioria das universidades brasileiras fruto da presença de estudantes negros e indígenas, ou ainda pelas consequências dessa presença que, institucionalmente, tem atingido as políticas institucionais de permaência, ou ainda pelas demandas voltadas às alterações curriculares propostas tanto por esses estudantes (e professores ${ }^{9}$ ) quanto pela implementação das Diretrizes Curriculares para a Educação das Relações Étnico-Raciais teria sido solucionado no interior do debate da comunidade acadêmica da UNEMAT, a ponto da aprovação da extensão desses políticas ter sido aprovada sem grandes impasses? O que se passou no interior da universidade provocando mudanças tão acentuadas em relação à aceitação da presença negra no ensino superior em Mato Grosso? Que elementos podem ser elencados de modo a dialogar com a posição dos conselheiros em 2015? Por quais motivos não se verificou qualquer tipo de polarização em relação à matéria em votação ? E por que foi possível aprovar a prorrogação do Piier/Unemat sem que houvesse um único dado ou informação produzida ao longo de uma década acerca dos estudantes cotistas (2205-2015) ? ${ }^{10}$

Ainda que pouco explorada na literatura especializada possui destaque a gestão universitária nos processos de implementação, acompanhamento e avaliação de tal propositura. A experiência da Universidade do Estado de Mato Grosso pode ser importante no contexto nacional em função da possível fusão entre o racismo estrutural e a condução da política. Ao lançar seu olhar para os encadeamentos possibilitados pela sanção da Lei 12.711/12, Santos (2020: 136 e 137) assevera que

\footnotetext{
${ }^{9}$ A Lei № 12.990 foi promulgada em 9 de junho de 2014, instituindo a "Reserva aos negros $20 \%$ (vinte por cento) das vagas oferecidas nos concursos públicos para provimento de cargos efetivos e empregos públicos no âmbito da administração pública federal, das autarquias, das fundações públicas, das empresas públicas e das sociedades de economia mista controladas pela União". A partir desta lei os concursos públicos para acesso ao ensino superior para docentes passaram a obrigatoriamente, adotar uma porcentagem de suas vagas nos certames destinadas a candidatos autodeclarados e hetero identificados como pretos ou pardos. Aqui reside uma das origens das comissões de verificação fenotípica que vem se disseminando em Instituições de Ensino Superior.

10 Para conhecer a íntegra das resoluções que amparam às políticas de ação afirmativa na Universidade do Estado de Mato Grosso, consultar:

<http://www.unemat.br/legislacao/index.php?id_res=1651> (para a Resolução 200/2004Conepe) e <http://www.unemat.br/legislacao/index.php?id_res=3150> (para a Resolução 086/2015- Conepe que prorrogou o Piier/Unemat).
} 
Os beneficiários vinham enfrentando preconceitos, em função de seus valores, culturas e conhecimentos não reconhecidos nas IES. O acesso aos dados relativos às ações afirmativas nem eram disponibilizados aos pesquisadores, e que as instituições não vinham estimulando estudos e pesquisas sobre suas políticas com vistas a seu constante aprimoramento. As instituições não promoviam acompanhando (sic) os seus estudantes, em especial os cotistas, com o objetivo de detectar tendências de evasão e abandono e atuar de modo preventivo. Igualmente não se preocupavam com as trajetórias profissionais dos egressos.

Na busca de dialogar com as questões que se impõem no atual momento lançaremos uma hipótese, qual seja: as vagas destinadas a estudantes negros auto-declarados têm sido ocupadas, sistematicamente, por outros grupos sociais com total acordo e plena consciência dos gestores universitários, logo, não haveria tensionamento latente, visto que todos àqueles elementos aos quais as políticas de ação afirmativa tem se estruturado não estariam de fato sendo implementados, de modo que as dinâmicas produzidas pelo colonialistas estariam se perpetuando e, sucessivamente, operacionando-se para além daqueles sujeitos da diáspora.

Hipótese extrema que carece de comprovação. Antes de avançarmos na hipótese extrema, é preciso que se assegure a pertinência e validade do Piier/Unemat. Integrante de um extenso rol de programas de ação afirmativa, o Piier/Unemat pôde se configurar em torno de candidatos negros autodeclarados, pois desde o ano de 2000 a UNEMAT cumpria legislação, aprovada no âmbito da Assembleia Legislativa, que determinava que $50 \%$ das vagas ofertadas deveriam ser ocupadas por egressos do sistema público de educação ${ }^{11}$.

Ao mesmo tempo o Piier/Unemat tem contribuído positivamente com os estudantes negros cujo ingresso ocorreu pelo Programa. Os estudantes negros e cotistas quando encontram ambiência que os permitem expressar seus pensamentos e conviç̧ões não têm dúvidas em relação à importância do Programa. Em pesquisa recentemente concluída, pesquisadora associada ao Núcleo de Estudos sobre Educação, Gênero, Raça e Alteridade (Negra) entrevistou estudantes negros e cotistas em dois dos maiores campi universitários da Unemat. Nos Campi Universitário Jane Vanini (Cáceres) e

\footnotetext{
${ }^{11}$ A Lei 7244/00 de 30 de dezembro de 1999 e sancionada em 03 de janeiro de 2000, dispõe sobre a reserva de vagas na Unemat para alunos oriundos da rede pública de ensino. Esta mesma Lei determina que o percentual mínimo a ser ocupado por egressos do sistema público de ensino é de $50 \%$. Para consulta, acessar: <http://www.al.mt.gov.br/storage/webdisco/leis/lei_2035.pdf>
} 
Sinop os depoimentos destes estudantes são bastante densos.

Por um lado, mencionam as dificuldades e a aridez da condição de "ser cotista" em uma universidade que parece não desenvolver qualquer atividade de acolhimento a estes estudantes; por outro, afirmam que o Piier/Unemat foi decisivo para que seus sonhos de cursar o ensino público superior se efetivassem.

Analisando os depoimentos dos estudantes negros e cotistas da Unemat, e que são compartilhados pela mencionada, não restam muitas dúvidas em relação ao que o Programa tem proporcionado de positivo - apesar das manifestações racistas e, em larga medida, contrários ao mesmo - a estes estudantes (COSTA, 2015: pp. 151-198).

Realizada esta breve caracterização das percepções dos estudantes cotistas, retomemos a hipótese extrema. Para que fosse elaborado o texto da Minuta que resultou na Resolução 200/2004-Conepe, foram realizados inúmeras atividades de sensibilização nos campi universitários, onde foram mobilizados todos os segmentos acadêmicos, bem como outros atores que apoiavam esta iniciativa.

Assim, o texto submetido e aprovado por um dos Conselhos Superiores de Unemat contava com o acúmulo e a experiência de outros programas de ação afirmativa, na modalidade cotas e com recorte étnico-racial.

O percentual de $25 \%$ em cada curso e por modalidade de oferta, ser este percentual "piso" e não "teto" - ou seja, a partir de 2005/2 e por dez anos haveria no mínimo $25 \%$ de estudantes negros auto-declarados -, o critério da autodeclaração e a ratificação deste critério pelo movimento negro eram características que atribuem algum grau de singularidade ao Programa da Unemat ${ }^{12}$.

Ao longo da primeira década, isto é, entre 2005 e 2015 e nas edições dos vestibulares sob a égide da nova resolução - a que prorrogou por igual período - há o sistemático descumprimento do que é previsto na legislação, sobretudo no que se refere à participação do movimento negro no prcesso de ratificação da auto-declaração.

O sistemático descumprimento tem sido motivo de distintas manifestações no âmbito da política interna ${ }^{13}$ e também já foi identificado em

\footnotetext{
12 Entre março e novembro de 2004 no âmbito da Comissão para Elaboração do Programa Institucional Cores e saberes (Cepics) foram realizados aproximadamente 14 eventos dentro e fora da Unemat. Entre os estudantes e servidores técnico-administrativos dúvidas rapidamente foram superadas e durante um seminário realizado em junho de 2004, notava-se que havia contrariedade à adoção de um programa de ação afirmativa, com recorte étnico-racial, em parcela do segmento docente (VIEIRA, 2007).

${ }^{13}$ Entre 2009 e 2015 um conjunto de ações foi realizado junto ao Ministério Público do Estado de Mato Grosso. De um modo geral, estes procedimentos não têm prosperado junto a este
} 
pesquisas acadêmicas como uma importante fragilidade do Programa (VIEIRA, 2012).

Se nos anos iniciais poderiam ser arrolados argumentos sobre a necessidade de adaptação aos "novos tempos" em função dos sistemas de ingresso implementados a partir da aprovação das cotas para negros na Unemat, rapidamente esta argumentação se desfez.

O sistemático descumprimento da legislação vigente e do que está previsto nas resolução que amparam a adoção de cotas na Unemat, amplamente divulgados junto aos gestores universitários, parece constituir uma estratégia que reúne por um lado a desmoralização do Programa e, concomitantemente, a possibilidade de assegurar a presença de não-negros ingressantes pelas cotas, daí a hipótese extrema.

Corroborando a hipótese extrema as crescentes denúncias que têm sido encaminhadas às instâncias universitárias; denúncias que têm cumprido todo o rito administrativo e para as quais nenhuma providência, que seja de conhecimento da Comunidade Acadêmica, tenha sido apresentada.

Assim, esta hipótese - batizada de extrema- que precisará ser desenvolvida à luz dos acontecimentos destes 12 (doze) anos de vigência de um programa de ação afirmativa com recorte étnico-racial, repousa sua principal linha de argumentação sobre o desenho institucional de ao não apurar as denúncias e deixar de cumprir integralmente às resoluções, estimula, por conseguinte, a ocupação destas vagas por candidatos não-negros, resultando na apropriação indevida de direitos da população negra por outros grupos sociais, estes já sobrerrepresentados no ensino superior no Brasil (VIEIRA, 2015).

\section{CONSIDERAÇÕES FINAIS}

Políticas de ação afirmativa são instrumentos de busca da realização do princípio da igualdade material conhecidas pela sociedade brasileira. 0 percentual constitucional em concursos públicos para pessoas com deficiência e a obrigatoriedade das cotas de gêneros em partidos políticos são alguns exemplos de como estas políticas já integravam as dimensões da cultura e da

órgão que, por definição constitucional, deve ser instalado em prol da defesa dos direitos de cidadania. Diante da não instauração de procedimentos jurídico-administrativos que determinem o cumprimento da legislação vigente, no segundo semestre de 2015 estas demandas foram protocoladas junto ao Conselho Superior do Ministério Público que ainda não se manifestou. A imprensa em Mato Grosso tem, em alguma medida, acompanhado todo este desdobramento. Para detalhes, consultar: http://www.reportermt.com.br/geral/estudante-loirateria-pintadocabelo-para-parecer-negra-e-passar-via-cota-racial/53035. 
política no interior da sociedade brasileira, portanto não há que se pensar em importações de modelos ou qualquer outro pensamento que se proponha a recusar iniciativas consagradas em termos sociais e asseguradas pela regulação normativa do Estado Nacional.

Adotadas por amplo conjunto de países, em diversos quadrantes, as ações afirmativas são retomadas nos anos iniciais do século XXI por universidades - públicas e privadas - a partir do Rio de Janeiro considerando a experiência e a influência da Conferência de Durban ${ }^{14}$.

Entre 2002 e 2012 uma grande polêmica se instaurou na sociedade brasileira em torno das políticas de ação afirmativa implementadas em inúmeras universidades. Curiosamente, os mesmos princípios e os mesmos contornos não eram fustigados como é o exemplo da previsão constitucional da ação afirmativa considerando a compleição física.

Esta "dupla percepção" pode sugerir que a polarização entre favoráveis e contrários revelou apenas parte do debate acerca do que as cotas para negros e as políticas de ação afirmativa com recorte étnico-racial podem trazer em seu bojo.

Provavelmente, não se trata exclusivamente da recusa dos instrumentos inerentes à política de ação afirmativa na medida em que a crítica destinou-se "apenas" àquelas adotadas nas universidades, no mercado de trabalho e em concursos públicos.

No caso da Unemat parece existir desdobramentos que merecem ser analisados com bastante acuidade. Aprovado em fins de 2004, e com vigência a partir do segundo semestre do ano seguinte, o Programa de Integração e Inclusão Étnico-racial da Unemat jamais foi implementado em sua plenitude.

Uma das "lacunas" mais evidentes tem sido a não participação do movimento negro para a ratificação do princípio da auto-declaração, o que tem permitido, com anuência dos gestores universitários, a crescente ocupação das vagas destinadas a negros auto-declarados por outros grupos sociais que possuem sobrerrepresentação no ensino superior, especialmente o público.

São diversas as vicissitudes encontradas pelos programas de ação afirmativa com recorte étnico-racial no Brasil. A partir de 2012 com a aprovação específica para as Instituições Federais de Ensino Superior a tendência é que situações como a verificada na Unemat tendam a ser minimizadas. Contudo,

\footnotetext{
${ }^{14}$ A III Conferência Mundial das Nações Unidas Contra o Racismo, Discriminação Racial, Xenofobia e Intolerância Correlata, realizada pela ONU em Durban, na África do Sul (2001), foi um marco importante que influenciou no estabelecimento de uma série de ações políticas público-estatais relativas à questão racial, como, por exemplo, as recomendações sobre a adoção das Políticas de Ações Afirmativas com recorte racial nas universidades públicas e a criação do Conselho Nacional de Combate à Discriminação.
} 
deve-se alertar que esta legislação alcança exclusivamente às instituições mencionadas.

Caberá aos órgãos de controle interno das universidades estaduais e ao Ministério Público fazer com que os direitos da população negra, tão arduamente alcançados, sejam efetivamente implementados sob pena de as práticas institucionalizadas do racismo perpetuarem-se.

\section{REFERÊNCIAS}

ADELMAN, Miriam. A voz e a escuta-Encontros e Desencontros Entre a Teoria Feminista e a Sociologia Contemporânea. Editora: Edgard Blucher, 2009.

\section{ALVES, J. A. Lindgren. A Conferência de Durban contra o racismo e a} responsabilidade de todos. Disponível em:

<http://www.scielo.br/scielo.php?script=sci_arttext\&pid=S0034- 73292002000200009>. Acesso em 28 de março de 2016.

BERNARDINO-COSTA, Joaze; SANTOS, Sales Agusto dos; SILVÉRIO, Valter Roberto. Relações raciais em perspectiva. Disponível em:

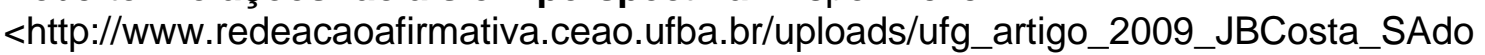
sSantos_VRSilverio.pdf>. Acesso em 18 de agosto de 2020.

BRASIL. Tribunal Superior Eleitoral. Eleições no Brasil: uma história de $\mathbf{5 0 0}$ anos, Brasília: TSE, 2014.

CARVALHO, José Murilo de. República, democracia e federalismo. Brasil 18701891. Disponível em: <http://www.scielo.br/pdf/vh/v27n45/v27n45a07.pdf>. Acesso em 02 de abril de 2016.

COSTA, Jacqueline da Silva. Cor e ensino superior: trajetórias e experiências de estudantes cotistas da Universidade do Estado de Mato Grosso - UNEMAT. Tese. Programa de Pós- graduação em Sociologia. Universidade Federal de São Carlos. São Carlos. 2015.

GOMES, Joaquim Barbosa. Ação Afirmativa e Princípio Constitucional da Igualdade, Rio de Janeiro: Reovar, 2001.

GUSMÃO, N. M.; SIMSON, O. R. M. A criação cultural na diáspora e o exercício da resistência inteligente. In.: Ciências Sociais Hoje, 1989. Anuário de Antropologia, Política e Sociologia. S. Paulo, Vértice/ANPOCS, 1989.

HALL, Stuart. A centralidade da Cultura: notas sobre as revoluções culturais do nosso tempo. Educação \& Realidade, Porto Alegre, v. 22, no2, p. 15-46, jul./dez. 1997.

HALL, Stuart. A Identidade Cultural na Pós-Modernidade. Trad.Tomaz Tadeu da Silva e Guacira Lopes Louro. Rio de Janeiro: DP\&A editora, 2005.

HALL, Stuart. Stuart Hall por Stuart Hall. Uma entrevista com Stuart Hall, de Kuan- 
Hsing Chen. In: Da Diáspora. Identidade e Mediações Culturais. Belo Horizonte. Editora UFMG. 2006

MOEHLECKE, Sabrina. Ação afirmativa: história e debates no Brasil. Disponível em: <http://www.scielo.br/pdf/cp/n117/15559.pdf>. Acesso em 25 de março de 2016.

PEREIRA, Sueli e ZIENTARSKI, Clarice. Políticas de Ação Afirmativa e Pobreza no Brasil.

Disponível em:

<http://www.emaberto.inep.gov.br/index.php/RBEP/article/viewFile/1913/1730>.

Acesso em 20 de março de 2016.

PRATT, Mary Louise. Imperial eyes: studies in travel writing and transculturation. 1992. Routledge, London and New York.

SADER, Eder. Quando os novos personagens entram em cena. Experiências e lutas dos trabalhadores da Grande São Paulo (1970-1980). 2ª ed., São Paulo: Paz e Terra, 1988.

SANTOS, Adilson Pereira dos. Gestão universitária e a lei de cotas. Curitiba: Appris, 2020.

VANALI, Ana Cristina e SILVA, Paulo Vinicius Baptista da. Ações afirmativas na pósgraduação stricto sensu: análise da universidade federal do paraná. Disponível em: <https://www.scielo.br/pdf/cp/v49n171/1980-5314-cp-49-171-86.pdf>. Acesso em 30 de agosto de 2020.

VIEIRA, Paulo Alberto dos Santos. A cor das cotas nas universidades brasileiras: ação afirmativa, raça e sobrerrepresentação de grupos sociais no ensino superior. Disponível em:

<http://www.abpn.org.br/Revista/index.php/edicoes/article/view/584>. Acesso em 29 de março de 2016.

VIEIRA, Paulo Alberto dos Santos. Cotas para negros em universidades brasileiras: significados contemporâneos da política de ação afirmativa. Tese. Programa de Pós-graduação em Sociologia. Universidade Federal de São Carlos. São Carlos, 2012.

VIEIRA, Paulo Alberto dos Santos. Políticas afirmativas, população negra e ensino superior em Mato Grosso: avaliando as cotas na Unemat, in: André Augusto Brandão (org.). Cotas raciais no Brasil: a primeira avaliação, Rio de Janeiro: DP\&A, 2007. 